\title{
Assessing the United States Grape Industry's Understanding of Fungicide Resistance Mitigation Practices
}

\author{
Charlotte L. Oliver, ${ }^{1}$ Monica L. Cooper, ${ }^{2}$ Melanie L. Lewis Ivey, ${ }^{3}$ \\ Phillip M. Brannen, ${ }^{4}$ Timothy D. Miles,${ }^{5}$ Walter F. Mahaffee, ${ }^{6}$ \\ and Michelle M. Moyer ${ }^{1 *}$
}

\begin{abstract}
In 2019, a national survey of 252 members of the United States grape industry from 20 states assessed knowledge perception of fungicide resistance management, application of that knowledge to vineyard practices, and knowledge acquisition sources. Overall, respondents demonstrated clear understanding of resistance management practices. The specific distribution of responses was influenced by the respondent's job role, duration of industry experience, and their farming operation size. Nationally, respondents were moderately familiar with the acronym FRAC (Fungicide Resistance Action Committee), with nearly 75\% indicating they could identify the FRAC code of a fungicide. They felt moderately competent they could design a fungicide program that adhered to resistance management principles. Respondents identified fungicide resistance as a serious problem nationally, and as a moderate problem in their own vineyards. They ranked practices that include rotating fungicides of different FRAC codes, avoiding multiple sequential applications of the same trade name or FRAC code, tank mixing with different FRAC codes, using multisite products in a spray program, routine sprayer maintenance and calibration, and good canopy management as very-to-extremely important in managing fungicide resistance; whereas practices such as rotating between trade names and tank mixing different trade names ranked slightly important. Respondents identified university-based extension programs as the primary information resource for fungicide efficacy and fungicide stewardship (resistance management). To maximize potential effect, these results suggest that future educational efforts should be aimed at improving practices for fungicide resistance stewardship and should align with the knowledgebase and demographic factors of the target audience - particularly their job role, experience, and size of operation.
\end{abstract}

Key words: disease management, FRAC, grape powdery mildew, grower perceptions, spray programs, viticulture

The development of pesticide resistance in a target pest can have severe consequences in any agricultural production system from both a direct effect on the system (e.g., crop loss, increased fungicide use) to indirect effects on the surrounding communities (e.g., social, economic, environmental impacts) (Gould et al. 2018). Fungicide resistance development, or reduced sensitivity, in the grape powdery mildew pathogen (Erysiphe necator Schwein.) offers a compelling timeline demonstrating the introduction, and then loss, of products for disease management. The first incidence of powdery mildew resistance was documented in the 1980s with benomyl (benzimidazole; FRAC 1)-resistant isolates of E. necator in New York (Pearson and Taschenberg 1980). Resistance to demethylase inhibitor (DMI; FRAC 3) was quick to follow (Gubler et al. 1996, Erickson and Wilcox 1997) and by the 2000s, resistance to quinone outside inhibitor (QoI; FRAC 11) (Baudoin et al. 2008, Miles et al. 2012, 2021), and field control failures with quinoxyfen (quinolines class; FRAC 13) were reported (Wilcox and Riegel 2012, Feng et al. 2018). More recently, resistance has been reported to succinate dehydrogenase

\begin{abstract}
${ }^{1}$ Washington State University - Irrigated Agriculture Research and Extension Center, 24106 North Bunn Road, Prosser, WA 99350; ${ }^{2}$ University of California-Cooperative Extension, 1710 Soscol Ave. Suite 4, Napa, CA 94559; ${ }^{3}$ The Ohio State University - CFAES Wooster,1680 Madison Avenue, Wooster OH 44691; ${ }^{4}$ University of Georgia - Plant Pathology Department, 2105 Miller Plant Sciences Building, Athens, GA 30602; ${ }^{5}$ Michigan State University - Department of Plant, Soil and Microbial Sciences, 578 Wilson Road, 105 CIPS, East Lansing, MI 48824; and ${ }^{6}$ United States Department of Agriculture-Agriculture Research Service Horticulture Crops Research Unit, 3420 NW Orchard Ave, Corvallis, OR 97331.

*Corresponding author (michelle.moyer@wsu.edu)
\end{abstract}

Acknowledgments: Funding for this survey was provided by the United States Department of Agriculture - National Institute for Food and Agriculture Specialty Crop Research Initiative Award No. 2018-03375 titled "FRAME: Fungicide Resistance Assessment, Mitigation and Extension Network for Wine, Table, and Raisin Grapes", USDA-ARS CRIS 5358-22000-041-00D, and USDA-NIFA Hatch 1016563. The authors would like to thank Gill Giese (New Mexico State University), Michela Centinari (The Pennsylvania State University), Hans Walter-Peterson (Cornell University), and Patty Skinkis and
Denise Dewey (Oregon State University), for assistance in distributing the survey to regional producers. The authors would also like to thank Malcom Hobbs (University of California Cooperative Extension) for assistance in survey data analysis. The use of trade, firm, or corporation names in this publication is for the information and convenience of the reader. Such use does not constitute an official endorsement or approval by the United States Department of Agriculture or the Agricultural Research Service of any product or service to the exclusion of others that may be suitable.

Supplemental data is freely available with the online version of this article at www.ajevonline.org.

Manuscript submitted Oct 2020, revised Dec 2020, accepted Jan 2021

This is an open access article distributed under the CC BY license (https:// creativecommons.org/licenses/by/4.0/).

By downloading and/or receiving this article, you agree to the Disclaimer of Warranties and Liability. The full statement of the Disclaimers is available at http://www.ajevonline.org/content/proprietary-rights-notice-ajev-online. If you do not agree to the Disclaimers, do not download and/or accept this article. doi: 10.5344/ajev.2021.20062 
inhibitors (SDHI; FRAC 7) (Graf 2018) and benzophenone fungicides (FRAC 50; formerly FRAC U8) (Kunova et al. 2016) in Europe. Since 2010, reports of multiple fungicide resistant isolates have been found in France where E. necator isolates were resistant to both DMI and QoI fungicides (Dufour et al. 2011).

Pathogen resistance is not only a problem for commercial disease management but is also challenging from a product development perspective. Bringing a new chemical class to market is costly (several hundreds of millions of dollars [USD]) and can take more than 11 years (McDougall 2016). Additionally, most new chemistries have single-site modes of action, which increases the risk of resistance development and shortens the time frame for obtaining a return on their investment (Mikaberidze et al. 2017). These factors are exacerbated by the limited number of cellular processes that can be targeted and disrupted using a fungicide, making it difficult to discover new chemical classes (Hahn 2014). Therefore, the practice of replacing fungicides with new chemistries once their efficacy declines is no longer practical (Hollomon 2015, Fisher et al. 2018). For these reasons, fungicide stewardship principles (e.g., best management practices) that focus on resistance management can promote the longevity of existing fungicides and provide the framework for appropriate introduction and suggested use patterns of new fungicides.

Improving our understanding of the process by which users adopt information will aide in improving outcomes around fungicide stewardship. In agricultural settings in the United States, a common method of information dissemination is through the Land Grant University system, where information is shared to a larger community via an expert affiliated with the Cooperative State Research, Education, and Extension Service (Cofer 2000). However, for this process to be successful, a distinction needs to be made between delivering information to an audience and supporting audience learning (Röling and Pretty 1997). This was apparent in a recent survey of California grapegrowers, who placed a greater value on experiential and peer-driven social learning pathways than formal learning experiences (Hoffman et al. 2015). In the case of fungicide resistance management, learning and application of specific mitigation practices is very important for the management of fungicide resistance in a population (Brent and Hollomon 2007).

To assess whether traditional fungicide stewardship messaging has had an effect on decision-making processes with respect to how fungicide programs are used and applied, a nationwide survey of the U.S. grape industry members was conducted. The survey was designed to capture industry members' concerns about fungicide resistance and awareness of principles and practices of fungicide stewardship. Specifically, the survey assessed respondents' attitudes toward various mitigation practices and what resources they use for gathering information on fungicides. The intent of the survey was to determine if specific topics related to fungicide resistance management are currently understood by this target audience and as a way to improve future efforts so that the developed content is understood and implementation is facilitated.

\section{Materials and Methods}

Survey design and content. The questionnaire was designed to capture industry members' self-reported knowledge of fungicide resistance, perceived importance of recommended management practices, and preferred educational resources for fungicide resistance and stewardship. The questionnaire was pretested by five industry professionals consisting of grapegrowers, viticulturists, and crop consultants. These professionals were queried relative to the structured feedback and clarity of the questions; with their suggestions, questions were modified to address their concerns. The final questionnaire consisted of four sections containing a total of 22 questions (Table 1). Nonweighted and discrete ("yes" or "no", "select one response" or "select all that apply") questions and Likert Scales were included to avoid response bias. The final format was completed using Qualtrics XM Online Survey Software (Qualtrics.com, LLC).

Participant recruitment and survey distribution. All survey and contact documents were reviewed by the Washington State University Office of Research Assurances and were deemed exempt from further review by the Institutional Review Board (IRB \#17383, "Pre-project Evaluation of Grape Grower Knowledge Base on Fungicide Resistance"). Participants were recruited by promoting the questionnaire through national outlets with a focus on viticulture, grape disease, and insect pest management and/or enology, including websites, social media, newsletters, grapegrower-based email listservs, United States Department of Agriculture Integrated Pest Management (USDA-IPM) worker groups, and grower meetings. The email listservs were curated by Cooperative State Research, Education, and Extension Service personnel or through private company contacts (i.e., larger vineyards, wineries, processing facilities, and packing houses). The questionnaire was delivered to industry members by email or through social media platforms (online survey), mail, or in-person using an audience response system (Turning Technologies), with periodic reminders. Mail and in-person survey responses were manually transferred to the Qualtrics interface. Each survey package included a cover letter, consent form, questionnaire (or link to questionnaire), and stamped return envelope (mail surveys only). No participation incentives were offered. The survey was conducted from December 2018 through May 2019.

Data analyses. Descriptive and statistical tests were performed with R (ver. 4.0.0, "Arbor Day") in R studio (ver. 1.2.5042, "Double Marigold"). Responses to knowledge perception and application questions were assigned a nonweighted numerical score (knowledge perception: $1=$ Not, 2 $=$ Slightly or Minor, $3=$ Somewhat or Moderate, $4=$ Moderately or Serious, 5 = Extremely or Devastating; knowledge application: 1 = Not important, 2 = Slightly important, $3=$ Moderately important, $4=$ Very important, $5=$ Extremely important; Table 1). The data distribution was confirmed to not be normal by Shapiro-Wilks test for normality (Shapiro and Wilks 1965) with unequal variances by Bartlett's test (Box 1953). The nonweighted numerical scores were then analyzed using a nonparametric Kruskal-Wallis one-way analysis of 
variance (ANOVA) of ranks (Kruskal and Wallis 1952) in agricolae (ver. 1.3-3) with a Holm's sequential Bonferroni adjustment (Holm 1979). If the effect was found to be significant $(p \leq 0.05)$, the responses were compared using a multiple comparisons Dunn's post-hoc test (rstatix, ver. 0.6.0) with a Holm's sequential Bonferroni adjustment (Tables 2 to 4). Graphs were constructed with ggplot2 (ver. 3.3.2). Data were considered to be significant at a $95 \%$ confidence level $(\alpha=0.05)$.

\section{Results}

Survey response rate and respondent demographics. A total of 304 survey responses from 20 states were returned by 30 May 2019. Seventeen percent $(n=52)$ of the responses were either incomplete or the respondents did not provide consent, so they were not included in the final survey count. A survey response was considered incomplete if demographic information was missing, or when three or more knowledge

Table 1 Questions and associated response categories used for the questionnaire.

\section{Demographic questions}

1. In what state(s) do you grow, manage, oversee, or consult for grapes? (Select all that apply.)

2. What is your primary role in the vineyard? (Select the option that best describes you.)

Vineyard owner (but no on-site management activities), Vineyard manager (makes vineyard management decisions for vineyards owned by you or the company you work for), Vineyard laborer (does not make vineyard management decisions), Viticulturist or Crop consultant (provides recommendations for vineyards owned by others)

3. What [pesticide applicator] certifications do you have? (Select all that apply.)

State or local pesticide applicator's license, Pest Control Advisor (PCA), Certified Crop Advisor (CCA), I do not have any of the above certification types

4. How long have you been in your field of employment?

Fewer than five years, 5 years to fewer than 10 years, 10 years to fewer than 20 years, 20 years or more

5. How many acres do you own, manage, oversee and/or consult for?

Fewer than 50 acres, 50 to fewer than 200 acres, 200 to fewer than 500 acres, 500 or more acres

\section{Knowledge perception questions}

1. How familiar are you with the acronym FRAC, as it relates to fungicide classifications? (Circle your answer.) Not at all familiar, Slightly familiar, Somewhat familiar, Moderately familiar, Extremely familiar

2. Do you know how to identify the potential FRAC group or classification of a fungicide? Yes, No

3. How competent do you feel at developing a vineyard fungicide program that adheres to fungicide resistance management principles? Not competent, Slightly competent, Somewhat competent, Moderately competent, Extremely competent

At what level do you believe fungicide resistance is a problem?

4. In vineyards across the United States (Check your response associated with each statement.) 1-Not a problem, 2-Minor problem, 3-Moderate problem, 4-Serious problem, 5-Devastating problem

5. In your vineyard(s) (Check your response associated with each statement.) 1-Not a problem, 2-Minor problem, 3-Moderate problem, 4-Serious problem, 5-Devastating problem

\section{Knowledge application questions}

How important do you believe each of the following practices are in managing fungicide resistance development?

(1-Not important, 2-Slightly important, 3-Moderately important, 4-Very important, 5-Extremely important)

1. Rotating between different product brand or trade names

2.Rotating between different FRAC groups

3. Never using the same brand name back-to-back in a spray program

4. Never using more than two sequential applications of the same FRAC group in a spray program

5. Tank mixing different fungicide trade names

6. Tank mixing different FRAC groups

7. Using multi-site products (such as sulfur, oil, or potassium bicarbonate) in a program

8. Routine sprayer calibration and maintenance

9. Good canopy management practices

\section{Knowledge acquisition sources}

1. How do you identify the potential FRAC group of a fungicide? (Select all that apply.) Look for group code on the fungicide label, Consult with my local fungicide supplier, Consult with my local Extension agent or Farm Advisor, Visit www.frac.org and search for the active ingredient, Other

2. Where/from whom do you get most of your information on fungicide use and effectiveness? (Select 1 response.) Manufacturers, Crop consultants, Colleagues (informal networks), Product labels or sell sheets, University Extension Service, Online resources with no official affiliation, Other

3. Where/from whom do you get most of your information on fungicide stewardship? (Select 1 response.) Manufacturers, Crop consultants, Colleagues (informal networks), Product labels or sell sheets, University Extension Service, Online resources with no official affiliation, Other 
perception responses were missing. A final total of 252 survey responses were used for analyses. Because response rates were low from some states, when we considered vineyard location, responses were grouped into general production regions based on their proximity to each other, and relative industry size and age: California; Northwest (Colorado, Idaho, Oregon, Washington); Northeast (New York, New Jersey, Pennsylvania, Rhode Island); Midwest (Illinois, Iowa, Michigan, Montana, Ohio, Wisconsin); Southeast (Georgia, Maryland, North Carolina); and Southwest (New Mexico, Oklahoma, Texas). Californian participants provided $35 \%$ of the responses, followed by participants from the Northwest (33\%), Southeast (12\%), Midwest (10\%), Northeast (9\%), and Southwest (4\%). Demographic information, including primary role of the respondent in the vineyard, number of acres man- aged and years in grape production, and certification types, by region, is presented in Table 5. Region was not used for further analysis but is provided to better understand the composition of survey participants across these production regions in the United States.

The majority of respondents, $61 \%$, classified themselves as a vineyard manager-defined as someone who makes management decisions for vineyards owned by themselves or their employer (Table 5 and Supplemental Figure 1). The next largest response segment, $29 \%$ of the responses, was from viticulturist or crop consultants-defined as someone who provides recommendations for vineyards owned by another (Table 5 and Supplemental Figure 2). A minority of responses, $7 \%$ and $3 \%$, were collected from vineyard owners (Table 5 and Supplemental Figure 3) and vineyard laborers

Table 2 Responses to questions on knowledge application by role in industry. FRAC, Fungicide Resistance Action Committee.

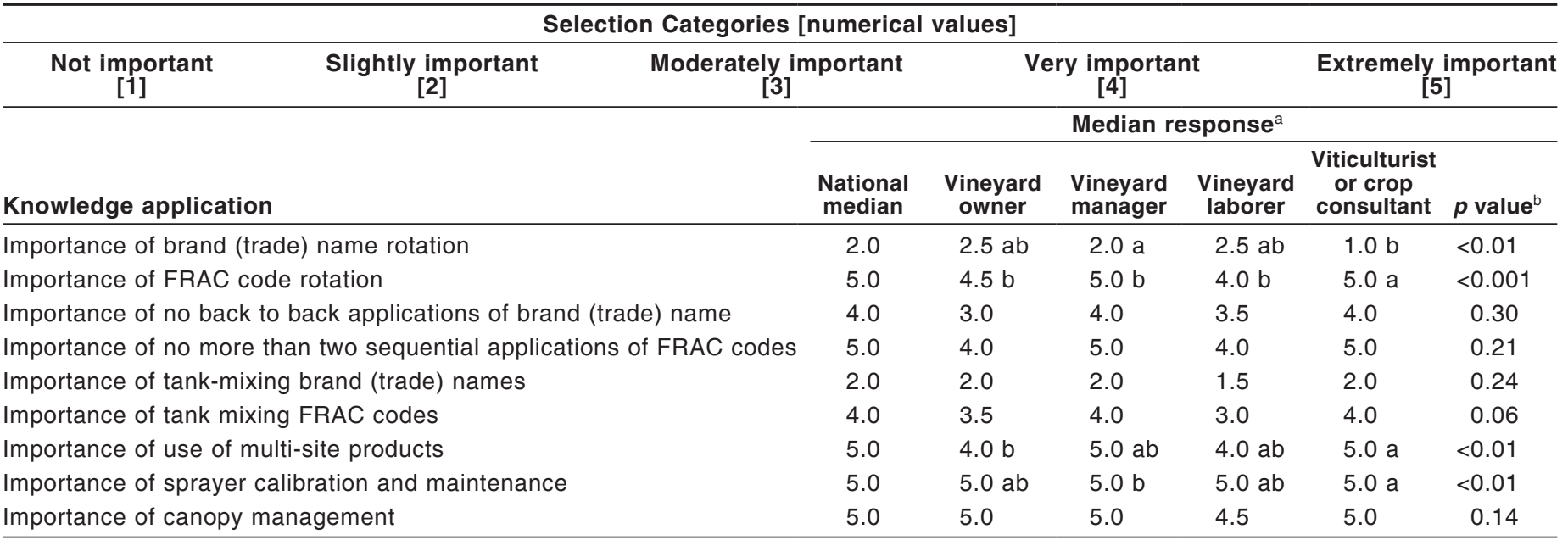

aDifferent letters across a row indicate significant differences between median response based on Dunn's post-hoc comparison of Kruskal-Wallis one-way analysis of variance (ANOVA). National median displayed for reference only and was not used in the analysis.

${ }^{\mathrm{b}} p$ value of Kruskal-Wallis one-way ANOVA.

Table 3 Responses to questions on knowledge application by years in industry. FRAC, Fungicide Resistance Action Committee.

\begin{tabular}{|c|c|c|c|c|c|c|c|}
\hline \multicolumn{8}{|c|}{ Selection Categories [numerical values] } \\
\hline Not important & $\underset{[2]}{\text { Slightly important }}$ & nportant & & ery importar & & Extremely & mportant \\
\hline \multirow{2}{*}{\multicolumn{2}{|c|}{ Knowledge application }} & \multicolumn{6}{|c|}{ Median response ${ }^{a}$} \\
\hline & & $\begin{array}{c}\text { National } \\
\text { median }\end{array}$ & $\begin{array}{c}\text { Fewer } \\
\text { than } \\
5 \mathrm{yr}\end{array}$ & $\begin{array}{c}5 \text { to } \\
\text { fewer } \\
\text { than } 10 \mathrm{yr}\end{array}$ & $\begin{array}{c}10 \text { to } \\
\text { fewer than } \\
20 \mathrm{yr}\end{array}$ & $\begin{array}{l}20 \text { or } \\
\text { more yr }\end{array}$ & value $^{p}$ \\
\hline \multicolumn{2}{|c|}{ Importance of brand (trade) name rotation } & 2.0 & 3.0 & 1.0 & 1.0 & 2.0 & 0.34 \\
\hline \multicolumn{2}{|c|}{ Importance of FRAC code rotation } & 5.0 & $5.0 \mathrm{~b}$ & $5.0 \mathrm{ab}$ & $5.0 \mathrm{a}$ & $5.0 \mathrm{ab}$ & 0.01 \\
\hline \multicolumn{2}{|c|}{ Importance of no back to back applications of brand (trade) name } & 4.0 & 4.0 & 4.0 & 4.0 & 4.0 & 0.89 \\
\hline \multicolumn{2}{|c|}{ Importance of no more than two sequential applications of FRAC codes } & 5.0 & 4.0 & 5.0 & 5.0 & 5.0 & 0.44 \\
\hline \multicolumn{2}{|c|}{ Importance of tank-mixing brand (trade) names } & 2.0 & 3.0 & 2.0 & 2.0 & 2.0 & 0.70 \\
\hline \multicolumn{2}{|c|}{ Importance of tank mixing FRAC codes } & 4.0 & 4.0 & 4.0 & 4.0 & 4.0 & 0.46 \\
\hline \multicolumn{2}{|c|}{ Importance of use of multi-site products } & 5.0 & 4.0 & 5.0 & 5.0 & 5.0 & 0.32 \\
\hline \multicolumn{2}{|c|}{ Importance of sprayer calibration and maintenance } & 5.0 & 5.0 & 5.0 & 5.0 & 5.0 & 0.70 \\
\hline \multicolumn{2}{|c|}{ Importance of canopy management } & 5.0 & 5.0 & 5.0 & 5.0 & 5.0 & 0.46 \\
\hline
\end{tabular}

aDifferent letters across a row indicate significant differences between median response based on Dunn's post-hoc comparison of Kruskal-Wallis one-way analysis of variance (ANOVA). National median displayed for reference only and was not used in the analysis.

${ }^{\mathrm{b}} p$ value of Kruskal-Wallis one-way ANOVA. 
(Table 5 and Supplemental Figure 4), respectively. Owners were defined as someone who owns a vineyard but provides no on-site management activities, and a laborer was defined as someone who works at a vineyard but provides no management decisions. There were low response rates in vineyard owners and vineyard laborers demographic categories, which needs to be considered when weighing the importance of the different venues of information.
The length of job experience (Table 5) was well represented across all four categories; the largest segment $(30 \%)$ were those who indicated they had worked in the industry for 20 or more years. The least represented category $(23 \%)$ were those who indicated they worked in the industry for fewer than 10 years. Small vineyards were the most represented in this survey (Table 5) with $48 \%$ of the respondents indicating they owned, managed, oversaw, or consulted for fewer than 50

Table 4 Responses to questions on knowledge application by acreage owned, managed, or overseen.

FRAC, Fungicide Resistance Action Committee.

\begin{tabular}{|c|c|c|c|c|c|c|c|}
\hline \multicolumn{8}{|c|}{ Selection Categories [numerical values] } \\
\hline Not important & \multirow[t]{3}{*}{$\underset{[2]}{\text { Slightly important }}$} & nportant & \multicolumn{3}{|c|}{ Very important } & \multicolumn{2}{|c|}{$\begin{array}{l}\text { Extremely important } \\
{[5]}\end{array}$} \\
\hline \multirow[b]{2}{*}{ Knowledge application } & & \multicolumn{6}{|c|}{ Median response $^{a}$} \\
\hline & & $\begin{array}{c}\text { National } \\
\text { median }\end{array}$ & $\begin{array}{l}\text { Fewer than } \\
50 \text { acres }\end{array}$ & $\begin{array}{l}50 \text { to fewer } \\
\text { than } 200 \\
\text { acres }\end{array}$ & $\begin{array}{c}200 \text { to } \\
\text { fewer than } \\
500 \text { acres }\end{array}$ & $\begin{array}{l}500 \text { or } \\
\text { more } \\
\text { acres }\end{array}$ & $p$ value ${ }^{b}$ \\
\hline Importance of branc & name rotation & 2.0 & $3.0 \mathrm{a}$ & $1.5 \mathrm{~b}$ & $2.0 \mathrm{ab}$ & $1.0 \mathrm{~b}$ & $<0.001$ \\
\hline Importance of FRAC & otation & 5.0 & $5.0 \mathrm{~b}$ & $5.0 \mathrm{a}$ & $5.0 \mathrm{ab}$ & $5.0 \mathrm{a}$ & $<0.001$ \\
\hline Importance of no ba & ack applications of brand (trade) name & 4.0 & $3.0 \mathrm{~b}$ & $4.0 \mathrm{a}$ & $4.0 \mathrm{ab}$ & $4.0 \mathrm{a}$ & $<0.001$ \\
\hline Importance of no $\mathrm{m}$ & two sequential applications of FRAC codes & 5.0 & $4.0 \mathrm{~b}$ & $5.0 \mathrm{a}$ & $5.0 \mathrm{ab}$ & $5.0 \mathrm{a}$ & $<0.01$ \\
\hline Importance of tank- & rand (trade) names & 2.0 & 2.0 & 2.0 & 3.0 & 2.0 & 0.09 \\
\hline Importance of tank & RAC codes & 4.0 & $3.0 \mathrm{~b}$ & $4.0 \mathrm{ab}$ & $3.0 \mathrm{ab}$ & $4.0 \mathrm{a}$ & $<0.01$ \\
\hline Importance of use o & site products & 5.0 & $4.0 \mathrm{~b}$ & $5.0 \mathrm{a}$ & $5.0 \mathrm{ab}$ & $5.0 \mathrm{a}$ & $<0.001$ \\
\hline Importance of spray & ration and maintenance & 5.0 & $4.0 \mathrm{~b}$ & $5.0 \mathrm{a}$ & $5.0 a b$ & $5.0 \mathrm{a}$ & $<0.001$ \\
\hline Importance of cano & Igement & 5.0 & 5.0 & 5.0 & 5.0 & 5.0 & 0.24 \\
\hline
\end{tabular}

${ }^{2}$ Different letters across a row indicate significant differences between median response based on Dunn's post-hoc comparison of Kruskal-Wallis one-way analysis of variance (ANOVA). National median displayed for reference only and was not used in the analysis.

${ }^{\mathrm{b}} p$ value of Kruskal-Wallis one-way ANOVA.

\begin{tabular}{|c|c|c|c|c|c|c|c|}
\hline \multirow[b]{2}{*}{ Demographic/description } & \multicolumn{7}{|c|}{ Responses (\%) } \\
\hline & $\begin{array}{l}\text { National } \\
(\mathrm{n}=252)\end{array}$ & $\begin{array}{l}\text { California } \\
(n=88)^{b}\end{array}$ & $\begin{array}{l}\text { Northwest } \\
(\mathrm{n}=83)\end{array}$ & $\begin{array}{l}\text { Northeast } \\
(\mathrm{n}=23)\end{array}$ & $\begin{array}{l}\text { Midwest } \\
(\mathrm{n}=25)\end{array}$ & $\begin{array}{l}\text { Southeast } \\
(\mathrm{n}=30)\end{array}$ & $\begin{array}{c}\text { Southwest } \\
(n=9)\end{array}$ \\
\hline \multicolumn{8}{|l|}{ Primary vineyard role } \\
\hline Vineyard owner & 7.1 & 1.1 & 9.6 & 13.0 & 0.0 & 20.0 & 0.0 \\
\hline Vineyard manager & 60.7 & 45.5 & 50.6 & 87.0 & 88.0 & 70.0 & 100.0 \\
\hline Vineyard laborer & 3.2 & 2.3 & 6.0 & 0.0 & 0.0 & 3.3 & 0.0 \\
\hline Viticulturist or crop consultant & 29.0 & 51.1 & 33.7 & 0.0 & 12.0 & 6.7 & 0.0 \\
\hline \multicolumn{8}{|l|}{ Years in industry } \\
\hline Fewer than 5 years & 23.0 & 20.5 & 21.7 & 13.0 & 12.0 & 43.3 & 33.3 \\
\hline 5 years to fewer than 10 years & 22.6 & 26.5 & 22.9 & 17.4 & 16.0 & 20.0 & 33.3 \\
\hline 10 years to fewer than 20 years & 24.6 & 30.7 & 21.7 & 17.4 & 28.0 & 16.7 & 11.1 \\
\hline 20 or more years & 29.8 & 22.7 & 33.7 & 52.2 & 44.0 & 20.0 & 22.2 \\
\hline \multicolumn{8}{|l|}{ Acreage managed } \\
\hline Fewer than 50 acres & 48.0 & 23.9 & 34.9 & 69.6 & 76.0 & 93.3 & 100.0 \\
\hline 50 to fewer than 200 acres & 15.1 & 11.4 & 19.3 & 30.4 & 12.0 & 6.7 & 0.0 \\
\hline 200 to fewer than 500 acres & 8.3 & 17.0 & 7.2 & 0.0 & 0.0 & 0.0 & 0.0 \\
\hline 500 or more acres & 28.6 & 47.7 & 38.6 & 0.0 & 12.0 & 0.0 & 0.0 \\
\hline \multicolumn{8}{|l|}{ Certifications } \\
\hline State or local pesticide applicator's license & 45.9 & 22.7 & 52.7 & 82.6 & 59.3 & 70.0 & 44.4 \\
\hline Pest control advisor & 10.6 & 20.0 & 7.5 & 0.0 & 7.4 & 0.0 & 0.0 \\
\hline Certified crop advisor & 19.9 & 41.8 & 11.8 & 0.0 & 3.7 & 0.0 & 0.0 \\
\hline No listed certifications & 23.6 & 15.5 & 28.0 & 17.4 & 29.6 & 30.0 & 55.6 \\
\hline
\end{tabular}

${ }^{a}$ Northwest: Colorado, Idaho, Oregon, Washington; Northeast: New York, New Jersey, Pennsylvania, Rhode Island; Midwest: Illinois, Iowa, Michigan, Montana, Ohio, Wisconsin; Southeast: Maryland, North Carolina, Georgia; Southwest: New Mexico, Oklahoma, Texas.

${ }^{b}$ Number of responses from that state or region. 
acres. Large vineyard operations of 500 or more acres were the next highest represented category, with $29 \%$ of the responses. Moderately sized operations (50 to fewer than 200 acres), and moderately large operations (200 to fewer than 500 acres) were represented by $15 \%$ and $8 \%$ of the responses, respectively.

Survey participants were also asked to identify if they held any type of certification or pesticide applicators license. Overall, $76 \%$ of the respondents indicated that they held at least one type of certification or pesticide applicators license, and $12 \%(n=30)$ indicated they held more than one license or certification. Forty-six percent $(n=131)$ indicated they had a local or state pesticide applicator's license, 10\% $(\mathrm{n}=29)$ indicated they were certified crop advisors, and 20\% $(n=56)$ indicated they were pest control advisors. Only 24\% $(n=68)$ of the respondents indicated they did not hold any type of certification or pesticide applicator's license.

Self-reported knowledge of fungicide resistance and mitigation. Familiarity with the acronym FRAC. Respondent's job role, duration of experience, and size of farming operation significantly influenced whether they were familiar with the FRAC (Fungicide Resistance Action Committee) acronym (Figure 1). Overall, viticulturists or crop consultants were more likely to indicate greater familiarity with the acronym, compared to vineyard managers and vineyard laborers (Figure 1). Respondents who were relatively new to the industry (fewer than five years) were less familiar with the acronym than those with more than 10 years' experience (Figure 1). Respondents working in smaller operations (fewer than 50 acres) were less familiar with the acronym compared to those who worked at moderate (50 to fewer than 200 acres) or large (over 500 acres) operations.

Ability to identify fungicide FRAC group. Nationally, 75\% $(\mathrm{n}=189)$ of the respondents indicated they could identify the FRAC group or code of a fungicide. Respondent's job role, duration of experience, and the size of farming operation significantly affected responses. Vineyard owners were significantly less likely to report the ability to identify a FRAC group than a viticulturist or crop consultant (Figure 2). Respondents with fewer than five years of experience were also less likely to report the ability to identify a FRAC group than those with more than 10 years of experience (Figure 2). There were fewer respondents who worked at small vineyards (50 acres or fewer) who indicated they could identify a FRAC group of a fungicide compared to respondents at operations with 50 acres or more (Figure 2).

How a FRAC group was identified. Those who indicated they could identify a fungicide's FRAC group were then asked what sources they use to identify that FRAC group (Figure 3). Respondents were instructed to make multiple selections (252 individual respondents provided 319 responses). Nationally, $42 \%(n=135)$ indicated they look for the code on the fungicide label, $18 \%(\mathrm{n}=58)$ consult with their local fungicide supplier, $14 \%(\mathrm{n}=44)$ visit the website www.frac. org, $14 \%(n=44)$ indicated they consulted with their local extension agent, and $11 \%(\mathrm{n}=36)$ selected "Other". For individuals selecting "Other," common sources of identifying the FRAC group or classification of a fungicide included farm management software, unaffiliated online sources, and regional grower meetings.

Vineyard owners $(n=18)$ were more than $5 \%$ above the national average for using www.frac.org $(39 \% ; n=7)$. Because of the low response, it is not clear if vineyard laborers $(n=9)$ use of labels $(56 \% ; n=5)$, and local extension services $(22 \%$; $\mathrm{n}=2$ ) differ from the national average. Viticulturists or crop consultants $(\mathrm{n}=92)$ used labels less than the national average $(34 \% ; n=31)$ and relied more on "Other" sources $(23 \%$; $\mathrm{n}=21)$ than the national average.

Those who have been in the industry for fewer than five years $(n=51)$, or from 10 to fewer than 20 years $(n=93)$ were within $5 \%$ of the national responses (Figure 3 ). Those who

\section{Familiarity with the acronymn FRAC}
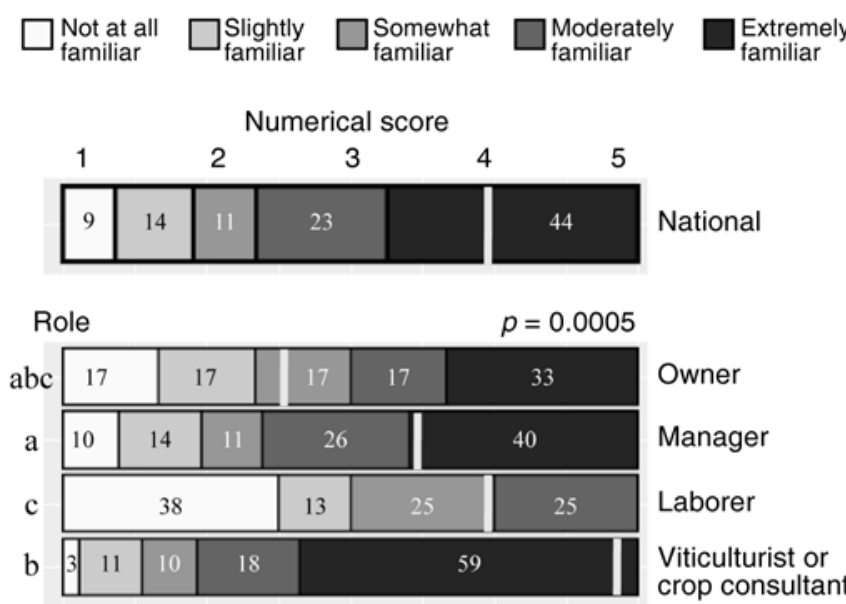

Owner Manager Laborer Viticulturist or crop consultant

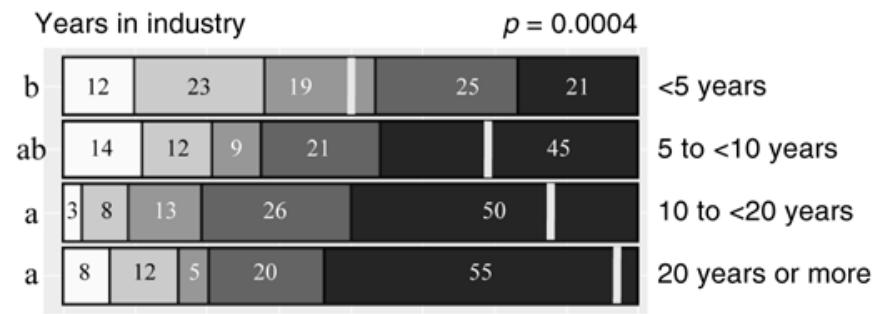

Size of operation $\quad p<0.0001$

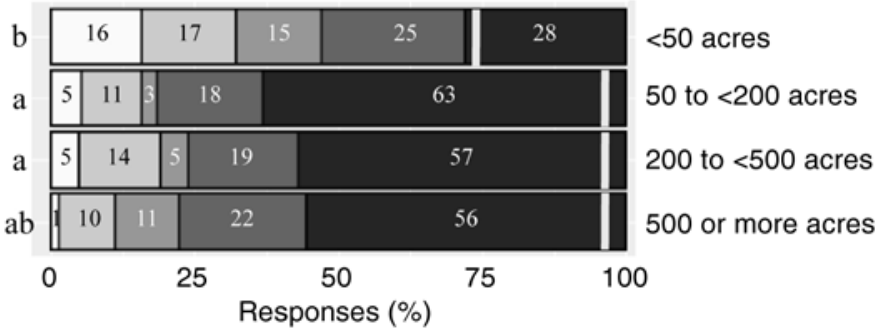

Figure 1 Familiarity with the acronym FRAC (Fungicide Resistance Action Committee) as reported nationally and by role in the industry, by years in the industry, and by size of operation (percentage of total responses collected across the nation). Numbers within each bar correspond to the percentage of the responses in that category (bottom axis). The vertical white line corresponds to the median of the nonweighted numerical score assigned to the familiarity categories [1-Not at all, 2-Slightly, 3-Somewhat, 4-Moderately, 5-Extremely] (top axis). The $p$ values are the results of Kruskal-Wallis one-way analysis of variance of ranks with a Holm's sequential Bonferroni adjustment. Significant separations between factors from Dunn's post-hoc test is represented by lowercase letters in the left of the figure. 
have been in the industry for five to fewer than 10 years ( $\mathrm{n}=$ 71) were above the national average for consulting with their local extension agent or farm advisor $(20 \% ; n=14)$. Those who have been in the industry for 20 or more years $(n=104)$ were above the national average for using fungicide labels $(49 \% ; n=51)$.

Those who worked at smaller operations (fewer than 50 acres; $\mathrm{n}=131$ ) used fungicide labels more than the national average $(49 \% ; n=64)$ (Figure 3$)$. Individuals at moderately large operations (200 to fewer than 500 acres; $n=27$ ) used fungicide labels less than the national average $(30 \% ; n=8)$ and used their fungicide supplier more than the national average $(19 \% ; n=8)$. Respondents working with large operations (500 or more acres; $\mathrm{n}=100)$ used fungicide labels less than the national average $(35 \%, \mathrm{n}=35)$, and relied more on "Other" sources relative to the national average $(20 \%, \mathrm{n}=20)$.

Designing a fungicide program that adheres to resistance management principles. Nationally, $70 \%(\mathrm{n}=177)$ of the re-

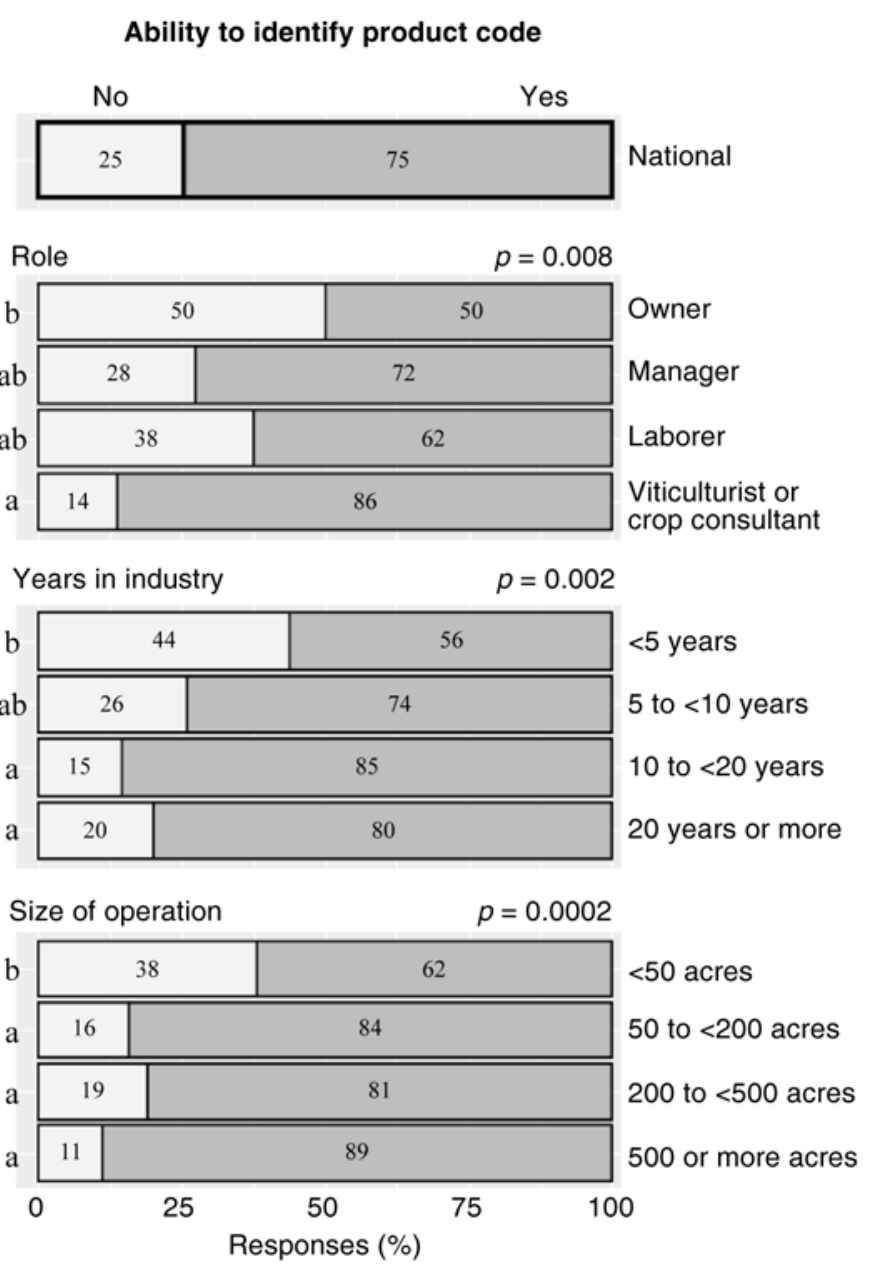

Figure 2 Ability to identify the FRAC (Fungicide Resistance Action Committee) group or classification of a fungicide as reported nationally and by role in the industry, by years in the industry, and by size of operation (percentage of total responses collected across the nation). Numbers within each bar correspond to the percentage of the responses in that category. The $p$ values are the results of Kruskal-Wallis one-way analysis of variance of ranks with a Holm's sequential Bonferroni adjustment. Significant separations between factors from Dunn's post-hoc test is represented by lowercase letters in the left of the figure. spondents considered themselves moderately to extremely competent in designing a fungicide program that adheres to fungicide resistance management principles (Figure 4). Only $8 \%(n=19)$ of all the respondents indicated that they did not feel competent. Job role, duration of experience, and size of farming operation significantly influenced an individual's response. Viticulturists or crop consultants reported a higher perceived competence at program design than vineyard owners (Figure 4). Those who have been in the industry for five years or fewer indicated less competence at this task than those who have been in the industry for five years or more (Figure 4). Participants from smaller operations (fewer than 50 acres) indicated lower competence at designing a fungicide program compared to those at moderate (50 to fewer than 200 acres) or large (over 500 acres) operations.

Concerns about fungicide resistance. Participants reported that fungicide resistance was a serious problem within the

\section{Sources for FRAC code identification}

\begin{tabular}{|l}
$\square$ Other $\quad \square \begin{array}{l}\text { Consult with my local } \\
\text { Extension agent or } \\
\text { Farm Advisor }\end{array}$ \\
$\square \begin{array}{l}\text { Consult with my local } \\
\text { Visit www.frac.org and search } \\
\text { for the active ingredient }\end{array}$ \\
$\begin{array}{l}\text { Look for group code } \\
\text { on the fungicide label }\end{array}$
\end{tabular}
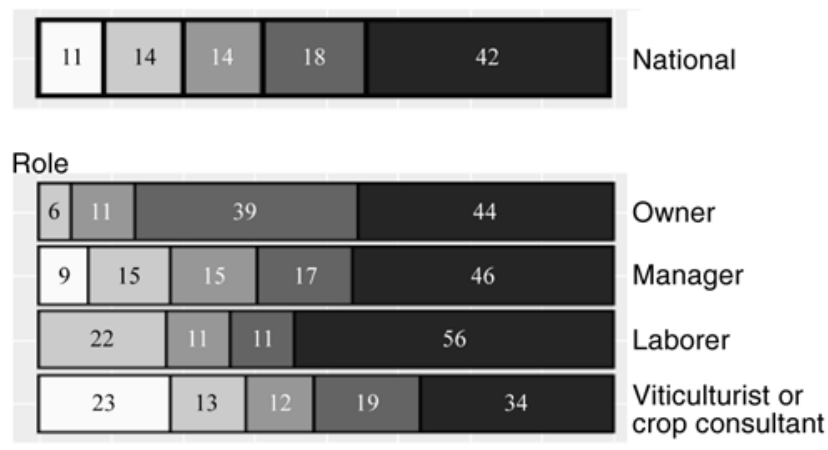

Years in industry

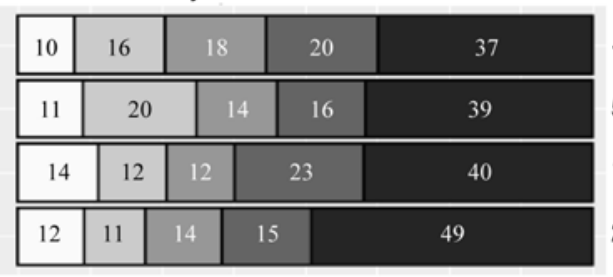

$<5$ years

5 to $<10$ years

10 to $<20$ years

20 years or more

Size of operation

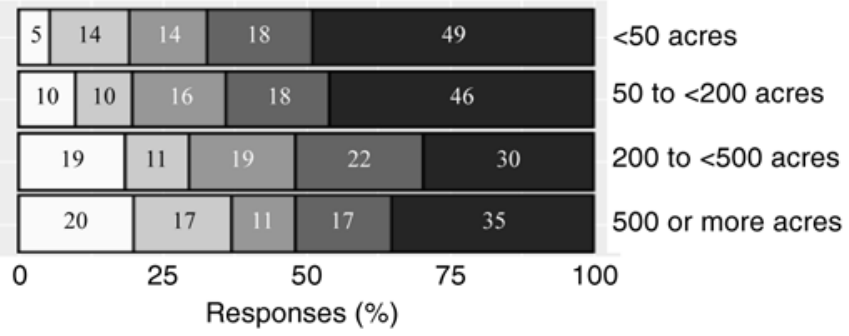

Figure 3 Resources respondents use to identify the FRAC (Fungicide Resistance Action Committee) code of a fungicide as reported nationally and by role in the industry, by years in the industry, and by size of operation (percentage of total responses collected across the nation). Numbers within each bar correspond to the percentage of the responses in that category. 
United States (Figure 5) and a moderate problem in their own vineyard (Figure 6). Unlike previous responses, job role and size of operation did not influence response, whereas years of experience did. When considering resistance as a national problem, those who have been in the industry for 10 years to fewer than 20 years felt it was more of a problem than those who have been in the industry for fewer than five years (Figure 5).

Knowledge application of resistance management practices. Nationally, respondents did not place as much importance on rotating brand names or tank-mixing brand names as they did for rotating FRAC group, not sequentially apply-
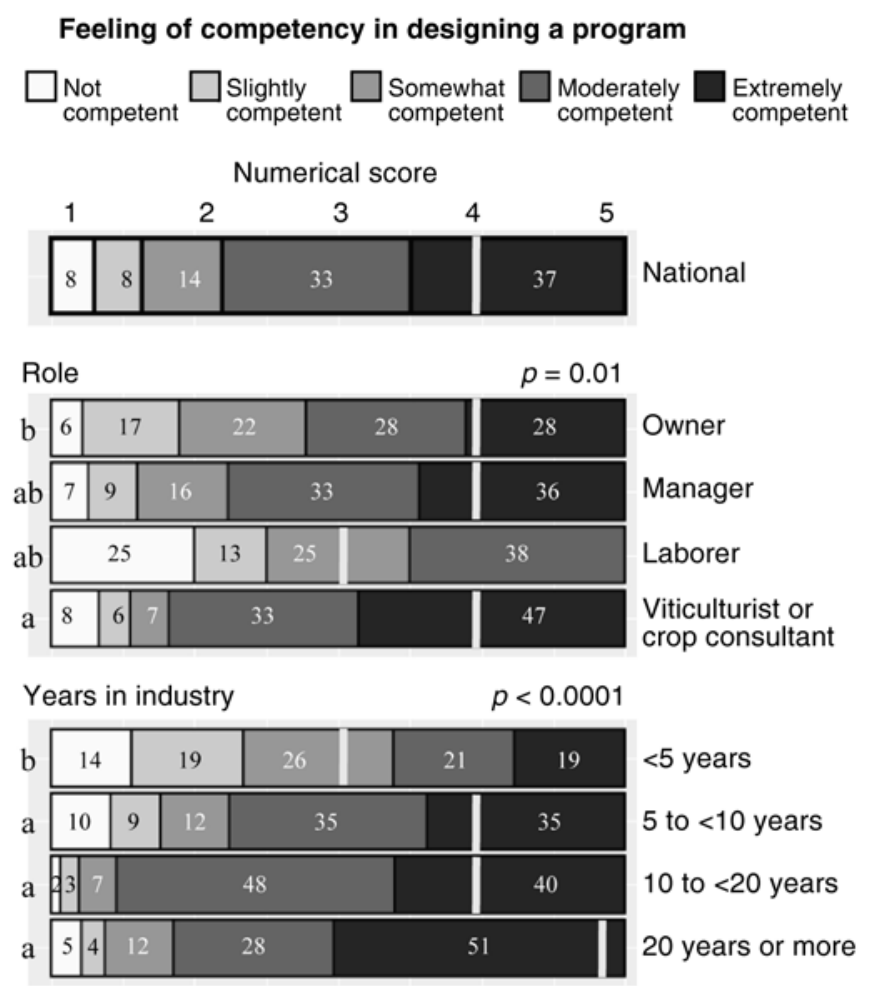

Size of operation $\quad p<0.0001$

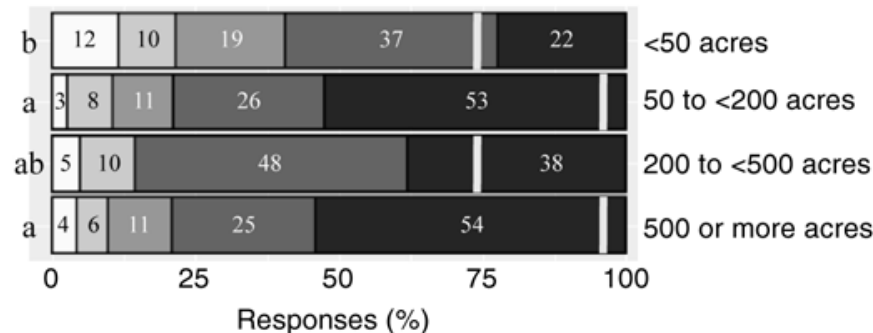

Figure 4 Percentage of total responses nationally for the respondent's perceived competence in ability to design a fungicide program that adheres to fungicide resistance management principles as reported nationally and by role in the industry, by years in the industry, and by size of operation (percentage of total responses collected across the nation). Numbers within each bar correspond to the percentage of the responses in that category (bottom axis). The vertical white lines correspond to the median of the nonweighted numerical score assigned to the response categories [1-Not at all, 2-Slightly, 3-Somewhat, 4-Moderately, 5 -Extremely] (top axis). The $p$ values are the results of Kruskal-Wallis one-way analysis of variance of ranks with a Holm's sequential Bonferroni adjustment. Significant separations between factors from Dunn's post-hoc test is represented by lowercase letters in the left of the figure. ing the same FRAC group, and using multisite fungicides (Figure 7). Avoiding sequential applications of fungicides by brand name and tank mixing with different FRAC groups were also considered more important for mitigating fungicide resistance. Of the cultural practices presented, canopy management (Figure 7) was considered extremely important and was not influenced by demographic factors.

Respondents' job role influenced how they ranked importance of rotating between brand names, rotating FRAC groups, using multisite products, and calibration and maintenance of sprayers (Table 2). Typically, viticulturists or crop consultants placed less importance on rotating between brand

\section{Problem of fungicide resistance in vineyards across the U.S.}
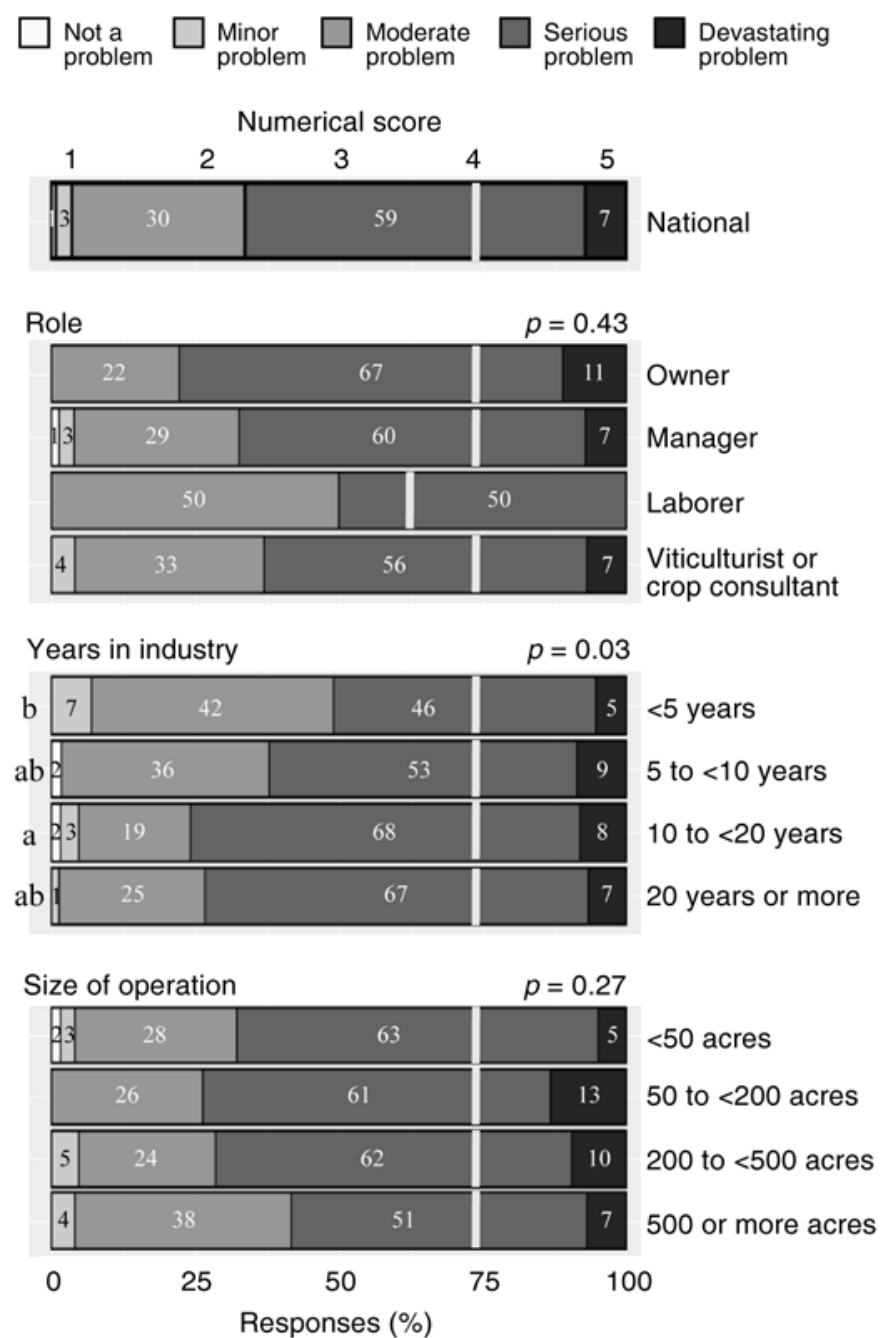

Figure 5 Respondent's perception of the problem of fungicide resistance as reported nationally across the United States and by role in the industry, by years in the industry, and by size of operation (percentage of total responses collected across the nation). Numbers within each bar correspond to the percentage of the responses in that category (bottom axis). The vertical white lines correspond to the mean of the nonweighted numerical score assigned to the response categories [1-Not a problem, 2-Minor problem, 3-Moderate problem, 4-Serious problem, 5-Devastating problem] (top axis). The $p$ values are the results of Kruskal-Wallis one-way analysis of variance of ranks with a Holm's sequential Bonferroni adjustment. Significant separations between factors from Dunn's post-hoc test is represented by lowercase letters in the left of the figure. 
names and more importance on sprayer calibration than did vineyard managers. They also placed more importance on using multisite products than vineyard owners, and placed more importance on rotating between FRAC groups than vineyard owners, managers, and laborers (Table 2).

Experience in the industry affected how they rated importance of rotating between FRAC groups (Table 3). Those who have been in the industry for 10 to fewer than 20 years placed more importance on rotating FRAC groups than those who have been in the industry for fewer than five years (Table 3).

Size of operation affected how they ranked rotating between brand names, rotating FRAC groups, avoiding sequen-
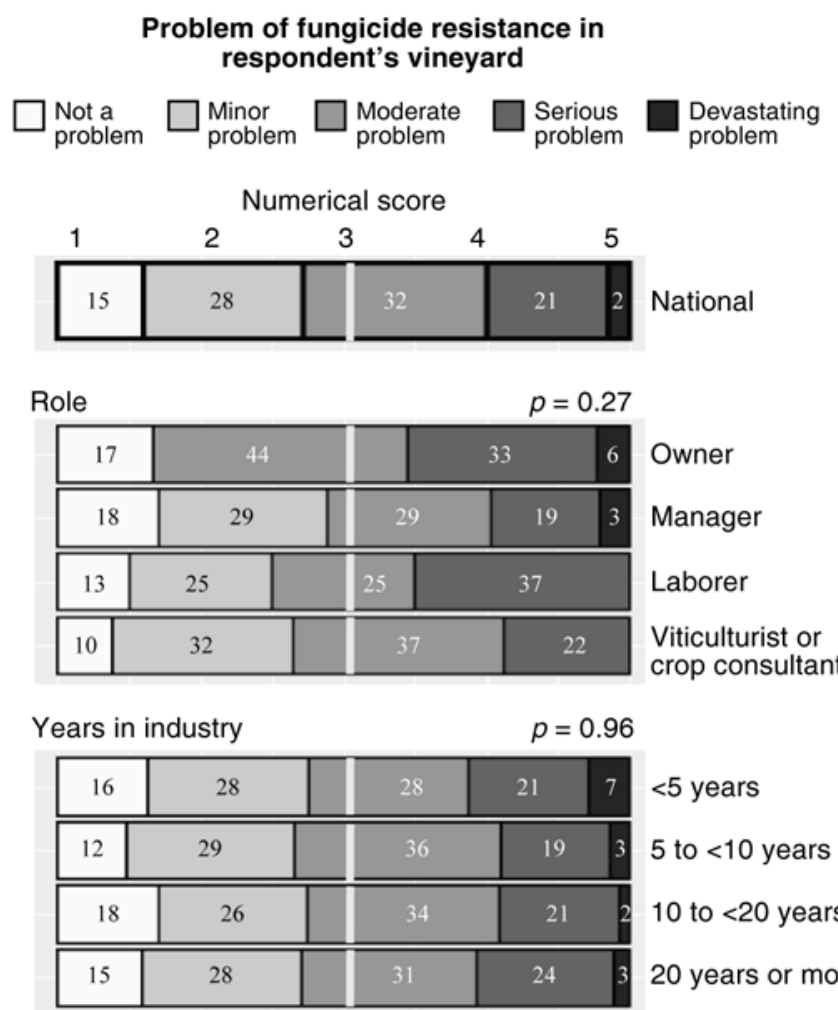

$<5$ years
5 to $<10$ years
10 to $<20$ years
20 years or more

Size of operation

\begin{tabular}{|c|c|c|c|c|c|}
\hline 1 & 29 & 26 & 22 & 4 & $<50$ acres \\
\hline 18 & 26 & 37 & 13 & 5 & 50 to $<200$ acres \\
\hline 10 & 29 & 33 & 24 & 5 & 200 to $<500$ acres \\
\hline 8 & 26 & 39 & 25 & & 500 or more acres \\
\hline ] & 25 & & & 10 & \\
\hline
\end{tabular}

Figure 6 Respondent's perception of the problem of fungicide resistance within the respondent's vineyard as reported nationally and by role in the industry, by years in the industry, and by size of operation (percentage of total responses collected across the nation). Numbers within each bar correspond to the percentage of the responses in that category (bottom axis). The vertical white lines correspond to the mean of the nonweighted numerical score assigned to the response categories [1-Not a problem, 2-Minor problem, 3-Moderate problem, 4-Serious problem, 5-Devastating problem] (top axis). The $p$ values are the results of Kruskal-Wallis one-way analysis of variance of ranks with a Holm's sequential Bonferroni adjustment. Significant separations between factors from Dunn's post-hoc test is represented by lowercase letters in the left of the figure. tial applications of a FRAC group or brand name, tank mixing with fungicides of different FRAC groups, and sprayer calibration and maintenance (Table 4). Those individuals who work with or at small operations (fewer than 50 acres) placed more importance on rotating brand, and less importance on rotating FRAC groups, not using the same brand name backto-back, not using the same FRAC group back-to-back, the use of multisite products, and sprayer calibration than those who are associated with moderate (50 to fewer than 200 acres) and large (500 or more acres) operations (Table 4). Additionally, those who worked at smaller operations placed less importance on tank-mixing with fungicides of different FRAC groups than those who worked at large operations (Table 4).

Educational resources for fungicide mitigation management practices. Information sources for fungicide use and efficacy. Fungicide use and efficacy information is considered to be information on product ratings and performance. Nationally, "University Extension Service" was the most frequently listed source of fungicide use and efficacy information (34\%; $\mathrm{n}=110)$, followed by colleagues $(19 \% ; \mathrm{n}=60)$, crop consultants $(16 \% ; n=51)$, product labels or sell sheets $(16 \% ; n=50)$, manufacturers $(7 \% ; n=23)$, online resources with no affiliation $(8 \% ; n=25)$, and "Other" $(2 \% ; n=5)$ (Figure 8$)$. The common responses for "Other" were industry conferences.

The responses of vineyard owners $(n=23)$ were above the national average for using consultants $(22 \% ; n=5)$ and colleagues $(26 \% ; n=6)$, and below the national average for using university extension services $(13 \% ; n=3)$. Vineyard managers $(n=202)$ were within $5 \%$ of the national responses. Vineyard laborers $(\mathrm{n}=12)$ primarily relied on colleagues $(42 \% ; n=5)$ and university extension services $(25 \% ; n=$ $3)$. Consultants $(n=87)$ were below the national average for using other consultants $(7 \% ; n=6)$, and above the national average for using product labels $(21 \% ; n=18)$.

\section{Importance of practices for fungicide resistance management}

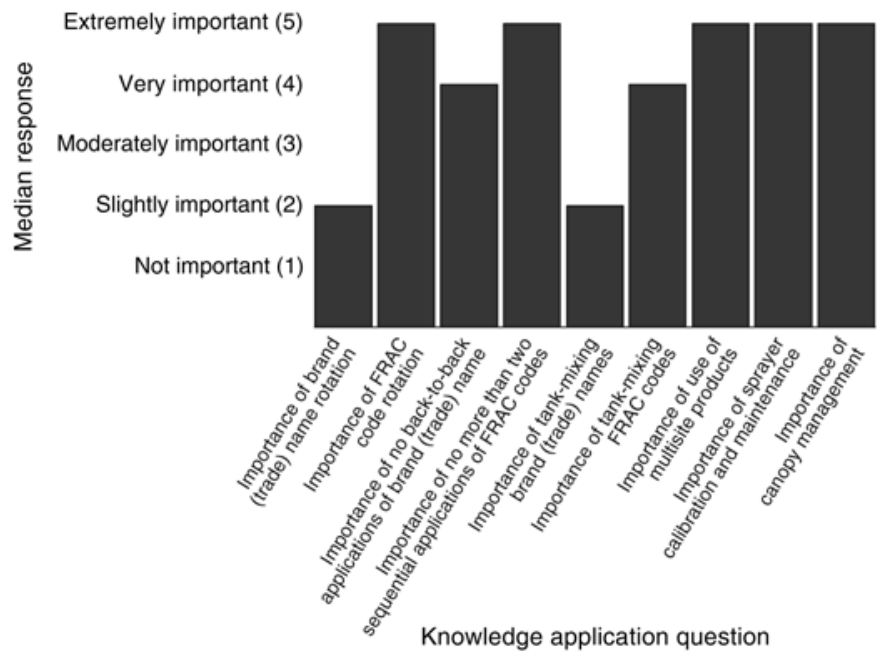

Figure 7 National responses (median values) to how important respondents felt different vineyard approaches and disease management practices were for mitigating fungicide resistance development. Medians were calculated using a nonweighted numerical score. FRAC, Fungicide Resistance Action Committee. 
The responses from individuals, separated by how long they have been in the industry, were all within $5 \%$ of the national average, as well as responses from individuals who worked with or at small operations (fewer than 50 acres; $n=$ 160). For moderately sized operations (50 to fewer than 200 acres; $\mathrm{n}=51$ ), they used consultants at a higher rate than the national average $(33 \% ; n=17)$, and university extension services were at a lower rate $(18 \% ; n=9)$. Moderately large operations (200 to fewer than 500 acres; $n=32$ ), used university extension services at a lower rate than the national average $(28 \% ; n=9)$, and online resources at a higher rate $(13 \% ; n=4)$. Large operations (500 or more acres; $n=81)$ used university extension services at a higher rate than the national average $(41 \% ; \mathrm{n}=33)$.

Information sources for fungicide stewardship. Fungicide stewardship information would be considered information on best use practices that promote product performance and

\section{Sources for fungicide use and efficacy}

$\begin{array}{lll}\square \text { Other } & \square \text { Online resources with } & \square \text { University } \\ \text { no official affiliation } & \text { Extension service } \\ \square \begin{array}{l}\text { Product labels } \\ \text { or sell sheets }\end{array} & \square \text { (informal networks) } & \square \text { Crop consultants } \\ & & \square \text { Manufacturers }\end{array}$
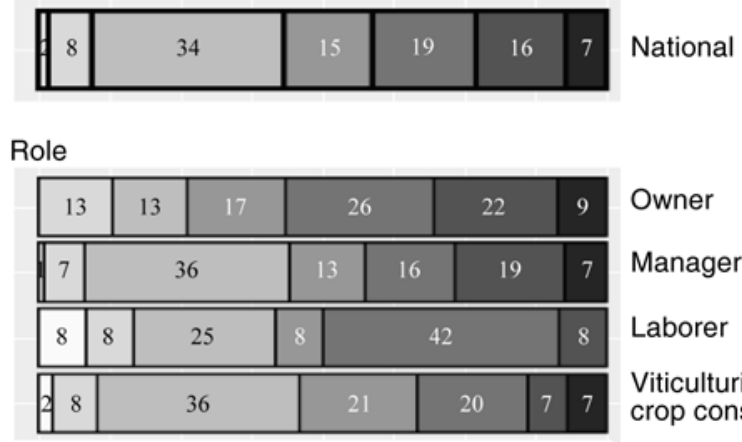

Owner
Manager
Laborer
Viticulturist or
crop consultant

Years in industry

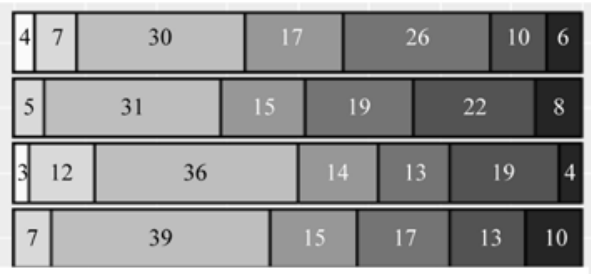

$<5$ years

5 to $<10$ years

10 to $<20$ years

20 years or more

Size of operation

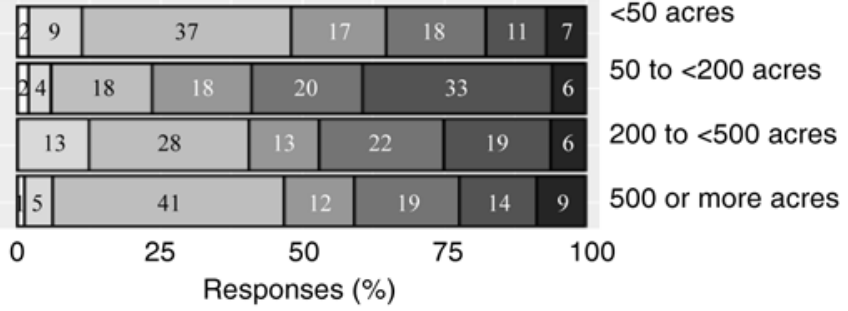

Figure 8 Where respondents were likely to acquire information on fungicide use and efficacy broken down by national response, their role in industry, their years in industry, and the size of their operation. Numbers within each bar correspond to the percentage of the responses in that category. longevity. Nationally, "University Extension Service" was the most frequently listed source for information on fungicide stewardship (38\%; $\mathrm{n}=152)$, followed by crop consultants $(19 \% ; n=77)$, colleagues $(19 \% ; n=76)$, product labels or sell sheets $(11 \% ; n=45)$, manufacturers $(8 \% ; n=30)$, online resources with no affiliation $(4 \% ; n=17)$, and "Other" $(1 \%$; $\mathrm{n}=3$ ) (Figure 9). A common response for "Other" was trade magazines.

Vineyard managers $(n=220)$ and viticulturists or crop consultants $(n=143)$ did not have responses that differed widely from the national responses. Vineyard owners ( $\mathrm{n}=$ 24) did not select manufacturers or provide other potential sources to obtain information on fungicide stewardship, and they most commonly selected university extension services $(42 \% ; \mathrm{n}=10)$ followed by consultants or colleagues $(25 \%$ each; $\mathrm{n}=6$ each). Vineyard laborers $(\mathrm{n}=13)$ also did not use "Other" sources or product labels, and more commonly

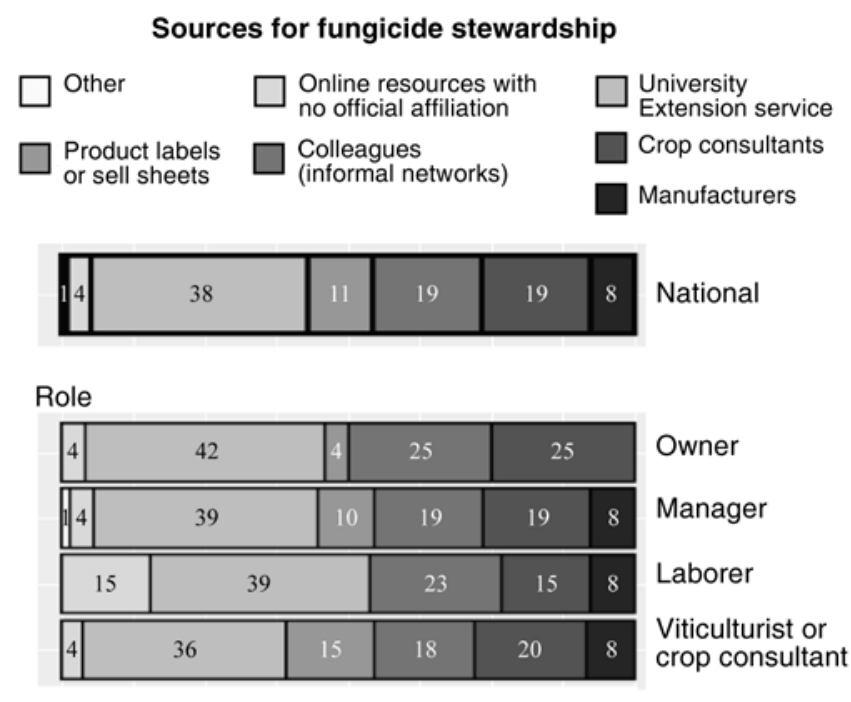

Years in industry

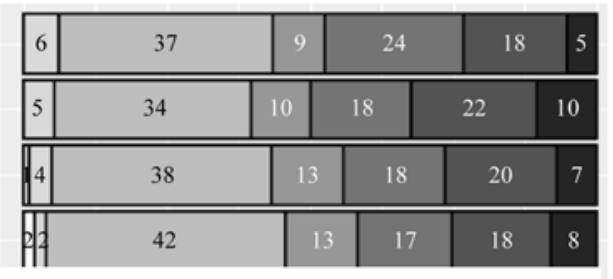

$<5$ years

5 to $<10$ years

10 to $<20$ years

20 years or more

Size of operation

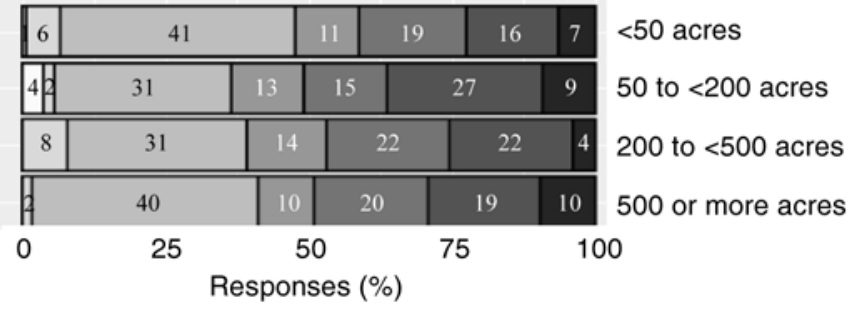

Figure 9 Where respondents were likely to acquire information on fungicide stewardship, broken down by national response, their role in the industry, their years in the industry, and the size of their operation. Numbers within the bars correspond to the percentage of the responses in that category. 
selected university extension services $(39 \% ; \mathrm{n}=5)$ or online resources $(15 \% ; n=2)$. The responses from individuals, separated by how long they have been in the industry, were all within $5 \%$ of the national average, as well as responses from individuals who worked with or at small operations (fewer than 50 acres; $\mathrm{n}=170$ ) or those at large operations (500 acres or more; $\mathrm{n}=124)$. Those who worked with or at moderately sized operations (50 to fewer than 200 acres; $\mathrm{n}=55$ ) more often selected consultants $(27 \% ; \mathrm{n}=15)$ and were less likely to select "University Extension Service" $(31 \% ; n=17)$ as their source of information for fungicide stewardship. Those at moderately large operations (200 to fewer than 500 acres; $n$ $=51$ ), also selected "University Extension Service" less often than the national average $(31 \% ; \mathrm{n}=16)$.

\section{Discussion}

The U.S. grape industry members who responded to this survey recognized fungicide resistance as a serious-to-devasting problem within the country ( $68 \%$; Figure 5), and indicated that it was a moderate-to-devastating problem within their own operations ( $55 \%$; Figure 6 ). This provides a baseline indication that fungicide resistance, toward the mitigation of longterm effects of widespread resistance and ensuing crop losses, is a potentially growing area of educational need within the grape industry in the United States.

A critical player in developing information and resources on fungicide resistance management is the international FRAC (FRAC 2020). In our survey, over $67 \%$ of respondents were either moderately or extremely familiar with the acronym FRAC (Figure 1) and its importance for fungicide resistance management. The FRAC best practices define fungicides broadly, based on their biochemical mode of action, resistance development risk, and cross resistance pattern, rather than as individual active ingredients. A result of this process is the grouping of chemistries by a code, which creates a quick and easy reference for comparing chemistries. In our survey, $75 \%$ of respondents could identify the FRAC group of a fungicide, and primarily sourced that information from the product label (42\%) (Figure 2). While it is impressive that the respondents can identify a product's FRAC group, only $42 \%$ of survey respondents source that information from the label. For those who do not use the fungicide label to identify a FRAC group, it would be worth learning if they do not refer to the label at all, if they do not know that the FRAC group is listed on the label, or if they do not spend sufficient time reading through the label to find this information.

Respondents to this survey indicated they felt "moderately competent" designing fungicide programs that adhere to resistance management principles, and using the principles described by FRAC (Figure 3). This indicates that education efforts can be further advanced to focus on more complex topics such as how to incorporate integrated disease and resistance management into a practical fungicide program. This was re-emphasized in their responses to further questions on the importance of different mitigation practices, where they demonstrated a more advanced understanding of fungicide stewardship principles. This included the ability to recognize the distinction in importance of rotating between fungicide brand names and rotating between FRAC group(s) (Figure 7). A different brand name may or may not indicate that two products have unique active ingredients or that they belong to different FRAC groups. Survey respondents categorized rotating FRAC groups in a fungicide program as extremely important, but rotating brand names as only slightly important. This probably indicates that they have an understanding that product rotation recommendations focus on rotating FRAC groups, and that rotating based on brand names may not achieve the desired outcome. While they also recognized that not using the same brand name of fungicide back-to-back is very important, they ranked the similarly phrased statement of not using sequential applications of the same FRAC group as extremely important (Figure 7). The same pattern of response was seen when asked to rank the importance of mixing products - tank mixing brand names as a strategy for fungicide resistance mitigation was seen as being slightly important, but tank mixing different FRAC groups was seen as very important. Additionally, respondents ranked practices such as using multisite products, canopy management, sprayer calibration, and maintenance as extremely important (Figure 7).

These responses demonstrate a sophisticated level of understanding of the nuances of avoiding sequentially using fungicides with the same mechanism. However, knowing that a practice is important is not necessarily indicative that those practices would be subsequently applied (Hillis et al. 2017). Additional studies are needed to confirm whether these activities to mitigate fungicide resistance are routinely adopted or used in vineyards.

The survey further indicates that basic educational efforts on fungicide program design that adhere to resistance management principles should be targeted toward those who have been in the industry for fewer than five years, and those who classify themselves as laborers (who do not make on-farm decisions), because both groups felt less competent at this task than the national average (Figure 4). Targeting these groups will provide educational backgrounds for individuals who will continue on in the industry (i.e., those with five or fewer years of experience), and for those who are typically involved in the final stage of fungicide program delivery (i.e., laborers) who might be better able to identify a mistake before a product is applied to the vineyard.

Additional demographic targets for educational efforts could be owners (e.g., no on-site management activities), and those who own or manage fewer than 50 acres because both groups ranked lower in their fungicide spray program design competency (Figure 4). Although it is likely that owners in this study may not make on-site management decisions, they probably provide general direction for their operations. If owners had a better understanding of how fungicide resistance affects their operation (both socially and economically), it could result in a trickle-down effect of policies or procedures that emphasize resistance mitigation practices. Finally, over $48 \%$ of our respondents nationwide were from smaller vineyard operations (fewer than 50 acres; Table 5), 
which have different production constraints than larger operations. This survey indicates there would be value in developing educational material targeted specifically to each group as opposed to the current "one size fits all approach." Many regional educational programs probably design materials targeting their regional demographics, for example, California and the Northwest focusing on materials for larger operations (Table 5). If smaller operations are accessing these resources, they may not find them appropriate for their operation. Specific to the winegrape industry, developing national materials that specifically focus on the challenges faced by smaller operations could have significant national reach. This could also improve consistent national messaging that would reinforce key resistance mitigation strategies across multiple resource venues, which is an important consideration for managing across-region pest management challenges (Wyenandt and Maxwell 2011).

Across all demographics, university extension services were the single most common source of information for fungicide efficacy and use (34\%; Figure 8), as well as fungicide stewardship (38\%; Figure 9) information. This was foreseeable, as the U.S. agricultural community tends to classify university extension services as a resource they can access for unbiased information and support for interpretation of research findings (Franz et al. 2010). However, the role of industry members' peer network, and interactions with consultants should not be ignored. Combined, peers and consultants constitute $35 \%$ of the information sources on fungicide use and efficacy, and $38 \%$ for fungicide stewardship. This provides an opportunity for extension personnel to capitalize on the strength of the informal colleague network as a communitybased learning tool to promote practice adoption among industry member groups (Prell et al. 2009, Franz et al. 2010, Rustagi et al. 2010, Hoffman et al. 2015). Developing and improving approaches to combine these two major forms of information delivery would help ensure that messaging on key concepts remains consistent across various industry outlets (Franz et al. 2010). One way to combine these activities would be to increase industry members' participation in extension demonstration practices, as "seeing is believing" (Leach et al. 2019). In more traditional educational settings, this could be done through hands-on group work at educational events to support peer problem solving or using recently acquired knowledge to "case-study" scenarios designed to emphasize key concepts and provide a practical context. By focusing on how an individual learns, and what is of practical use for their operation, educators can also increase engagement with adult learners in the farming community (Franz et al. 2010, Hoffman et al. 2015).

An additional opportunity to enhance education and engagement could be a focus on increasing the number of licensed or certified professionals in the industry. Nationally, $27 \%$ of respondents indicated they did not possess a formal certification or license that is typically associated with pest management (Table 5). This lack of licensing or certification was common in vineyard owners (Supplemental Figure 3) and vineyard laborers (Supplemental Figure 4), whereas vineyard managers (Supplemental Figure 1) and viticulturists or crop consultants (Supplemental Figure 2) held these certifications and also felt more competent in spray program design. Generally most licenses or certifications in pest management require continuing education credits and are often managed by durably structured state or professional organizations. Encouraging industry members to seek out a license or certification program that is appropriate for their region may directly help them improve practices on their farm (e.g., vineyard managers, vineyard owners), expand their businesses in the case of viticulturists or crop consultants, or improve their employment options (e.g., vineyard laborers), and would also become a consistent forum to deliver educational materials on fungicide resistance management.

There are always challenges associated with interpreting survey data because of sampling and response biases. To maximize our response rate $(\mathrm{n}=252)$ and minimize sampling bias, the survey was distributed through multiple methods and across multiple states. The multiple modes of delivery allowed for better tailoring of delivery style to meet local needs and considered state and/or regional differences in industry scale. Extension and industry winter (or off-season) meetings and workshops are one of the best ways to reach a large number of specialty crop stakeholders in a short period of time. However, these types of activities are typically attended by those in decision-making roles, or by those who need continuing education credits for licensing, which can introduce sampling bias. In an attempt to reduce the effect of sampling bias, we reached out to under-represented stakeholders, including crop consultants (outside of the western region), laborers, and fungicide representatives via social media, personal communication, regional newsletters, and industry listservs. While in the end, most respondents were vineyard managers and viticulturists or crop consultants who have some form of licensing credentials rather than vineyard owners or laborers, the former demographics were also the respondents defined as those making key management decisions in their operations. Arguably, this emphasizes the need to target educational programs to those respondents who were less likely to respond to the survey (i.e., laborers and owners) in an effort to increase knowledge and adoption of fungicide stewardship.

\section{Conclusion}

This survey captured information from the U.S. grape producers on their perceptions, understanding, and knowledge of fungicide resistance and its management. While the majority of the respondents indicated they felt fungicide resistance was a serious-to-devastating problem across the United States, they indicated a moderate familiarity with key concepts related to fungicide resistance messaging. More importantly, they were able to accurately identify important practices for managing fungicide resistance and to distinguish important concepts, such as the difference between brand name and FRAC group, and how that might influence fungicide resistance management practices. "University Extension Service" was the most commonly indicated source 
of fungicide use, efficacy, and stewardship information on a national scale, but was closely followed by informal peer networks and crop consultants. Several key demographics were identified as potential targets for increased messaging, including vineyard owners and laborers, small operations, and those who were relatively new to the industry. These networks should be considered when developing extension and educational programming on fungicide resistance management, to help promote recommended practice adoption and improve general understanding of key concepts across the industry.

\section{Literature Cited}

Baudoin A, Olaya G, Delmotte F, Colcol JF and Sierotzki H. 2008. QoI Resistance of Plasmopara viticola and Erysiphe necator in the mid-Atlantic United States. Plant Health Prog 9:25.

Box GEP. 1953. Non-normality and tests on variances. Biometrika 40:318-335.

Brent KJ and Hollomon DW. 2007. Fungicide Resistance in Crop Pathogens: How Can It Be Managed? 2nd ed. Fungicide Resistance Action Committee (FRAC), Brussels, Belgium.

Cofer DA. 2000. Informal Workplace Learning. Practice Application Brief \#10. US Office of Educational Research and Improvement, Washington DC. ERIC Publications, Columbus, Ohio.

Dufour M, Fontaine S, Montarry J and Corio-Costet M. 2011. Assessment of fungicide resistance and pathogen diversity in Erysiphe necator using quantitative real-time PCR assays. Pest Manag Sci 67:60-69.

Erickson EO and Wilcox WF. 1997. Distributions of sensitivities to three sterol demethylation inhibitor fungicides among populations of Uncinula necator sensitive and resistant to triadimefon. Phytopathology 87:784-791.

FRAC. 2020. About FRAC. https://www.frac.info/home/about-frac.

Feng X, Nita M and Baudoin AB. 2018. Evaluation of quinoxyfen resistance of Erysiphe necator (grape powdery mildew) in a single Virginia vineyard. Plant Dis 102:2586-2591.

Fisher MC, Hawkins NJ, Sanglard D and Gurr SJ. 2018. Worldwide emergence of resistance to antifungal drugs challenges human health and food security. Science 360:739-742.

Franz NK, Piercy F, Donaldson J and Richard R. 2010. How farmers learn: Implications for agricultural educations. J Rural Soc Sci 25:37-59.

Gould F, Brown ZS and Kuzma J. 2018. Wicked evolution: Can we address the sociobiological dilemma of pesticide resistance? Science 360:728-732

Graf S. 2018. Characterization of metrafenone and succinate dehydrogenase inhibitor resistant isolates of the grapevine powdery mildew Erysiphe necator. PhD Thesis, Technische Universität Kaiserslautern, Kaiserslautern, Germany.

Gubler WD, Ypema HL, Ouimette DG and Bettiga LJ. 1996. Occurrence of resistance in Uncinula necator to triadimefon, myclobutanil, and fenarimol in California grapevines. Plant Dis 80:902-909.

Hahn M. 2014. The rising threat of fungicide resistance in plant pathogenic fungi: Botrytis as a case study. J Chem Biol 7:133-141.
Hillis V, Lubell M, Kaplan J and Baumgartner K. 2017. Preventative disease management and grower decision making: A case study of California wine-grape growers. Phytopathology 107:704-710.

Hoffman M, Lubell M and Hillis V. 2015. Network-smart extension could catalyze social learning. Calif Agr 69:113-122.

Hollomon DW. 2015. Fungicide resistance: 40 years on and still a major problem. In Fungicide Resistance in Plant Pathogens. Ishii $\mathrm{H}$ and Holloman D (eds.), pp. 3-11. Springer, Tokyo.

Holm S. 1979. A simple sequentially rejective multiple test procedure. Scand J Stat 6:65-70.

Kruskal WH and Wallis WA. 1952. Use of ranks in one-criterion variance analysis. J Am Stat Assoc 47:583-621.

Kunova A, Pizzatti C, Bonaldi M and Cortesi P. 2016. Metrafenone resistance in a population of Erysiphe necator in northern Italy. Pest Manag Sci 72:398-404.

Leach AB, Hoepting CA and Nault BA. 2019. Grower adoption of insecticide resistance management practices increase with extensionbased program. Pest Manag Sci 75:515-526.

McDougall P. 2016. The cost of new agrochemical product discovery, development, and registration in 1995, 2000, 2005-8 and 2010 to 2014. R\&D expenditure in 2014 and expectations for 2019. A Consultancy Study for CropLife International, CropLife America and the European Crop Protection Association. United Kingdom.

Mikaberidze A, Paveley N, Bonhoeffer S and van den Bosch F. 2017. Emergence of resistance to fungicides: The role of fungicide dose. Phytopathology 107:545-560.

Miles LA, Miles TD, Kirk WW and Schilder AMC. 2012. Strobilurin (QoI) resistance in populations of Erysiphe necator on grapes in Michigan. Plant Dis 96:1621-1628.

Miles TD, Neill TM, Colle M, Warneke B, Robinson G, Stregiopoulus I and Mahaffee W. 2021. Allele-specific detection methods for QoI fungicide resistant Erysiphe necator in vineyards. Plant Dis 105:175-182.

Pearson RC and Taschenberg EF. 1980. Benomyl-resistant strains of Uncinula necator on grapes. Plant Dis 64:677-680.

Prell C, Hubacek K and Reed M. 2009. Stakeholder analysis and social network analysis in natural resource management. Soc Nat Resour 22:501-518.

Röling N and Pretty J. 1997. Extension's role in sustainable agricultural development. In Improving Agricultural Extension: A Reference Manual. Swanson B et al. (eds), pp. 246-262. Food and Agriculture Organization of the United Nations, Rome, Italy.

Rustagi D, Engel S and Kosfeld M. 2010. Conditional cooperation and costly monitoring explain success in forest commons management. Science 330:961-965.

Shapiro SS and Wilks MB. 1965. An analysis of variance test for normality (complete samples). Biometrika 52:591-611.

Wyenandt A and Maxwell NL. 2011. Evaluating fungicide recommendations for vegetable crops in the United States: Should more be done to limit the risks of fungicide resistance development? J Extension 49:3FEA8.

Wilcox WF and Riegel DG. 2012. Evaluation of fungicide programs for control of grapevine powdery mildew, 2011. Online publication. Plant Dis Manag Rep 6:SMF044. 